\title{
Development of a trainee ambassador programme for postgraduate training
}

\author{
Authors: Rachel Campbell, ${ }^{\mathrm{A}}$ Keith Gardiner, ${ }^{\mathrm{A}}$ Camille Harron ${ }^{\mathrm{A}}$ and Lyndsey Thompson ${ }^{\mathrm{B}}$
}

\begin{abstract}
Aims
To develop a trainee ambassador scheme to promote connections between trainees, highlight the benefits of training, and strengthen the link between Northern Ireland Medical and Dental Training Agency (NIMDTA) and trainees.
\end{abstract}

\section{Methods}

The 'VALUED' strategy was developed at NIMDTA to encourage high-calibre doctors to train and remain in Northern Ireland. Alongside this, the trainee ambassador scheme was developed to align with the ethos of the VALUED strategy through promotion of training. This scheme has been trainee-led through the Achieve Develop Explore Programme for Trainees (ADEPT) Clinical Leadership fellowship, with support from the postgraduate dean and senior educators.

All NIMDTA trainees were eligible to apply to the scheme providing they were on track for a favourable annual review of competence progression (ARCP) outcome and had supervisor approval. The applicants were required to complete an application form and in this explain how they would strengthen connections within the deanery and how they would promote training. Additionally we undertook a regional survey of trainees, with 235 responses, to gain a broader perspective on what was important to trainees.

\section{Results}

In their application form applicants were asked to identify ways they would promote training and strengthen relationships between NIMDTA and trainees. The responses were collated by the ADEPT fellow into themes. These formed the basis of the workstreams. These included promotion of academic and leadership opportunities, improved communication with NIMDTA, and development of social events. The regional survey responses supported the development of these work-streams in also highlighting these as areas for improvement.

In addition to leading on their projects, ambassadors are being provided with training to help them in their role, in areas such

Authors: ${ }^{A}$ Northern Ireland Medical and Dental Training Agency (NIMDTA); ${ }^{B}$ Belfast Health and Social Care Trust, Belfast, UK as project management. These projects include organisation of a roadshow where members of the deanery, along with trainee ambassadors, meet trainees at their place of work in an informal capacity to discuss opportunities available to trainees. This has received good feedback to date. Several ambassadors are in the process of setting up an academic network to promote research and quality improvement while another group are organising a series of social events to promote life-work balance among trainees.

\section{Conclusion}

In the first 6 months this scheme has been successful and has received good feedback. We will continue to develop and adapt based on feedback from trainees to ensure that, through the scheme, we are promoting a positive training experience for trainees in Northern Ireland, ensuring that they feel valued.

\section{Conflict of interest statement}

Nil noted. 